\title{
Commentary to: Effect of continuous ozone injection on performance and biomass accumulation of biofilters treating gaseous toluene
}

\author{
Jinying $\mathrm{Xi}^{1} \cdot$ Prakit Saingam $^{1} \cdot$ Feng Gu ${ }^{1} \cdot$ Hong-Ying $\mathrm{Hu}^{2} \cdot$ Xuefei Zhao ${ }^{1}$
}

Published online: 19 February 2016

(C) Springer-Verlag Berlin Heidelberg 2016

Commentary to: Appl Microbiol Biotechnol (2014)

98:9437-9446

DOI 10.1007/s00253-014-5888-z

We found that this article was inadvertently published twice in Applied Microbiology and Biotechnology. Citations on the article "Effect of continuous ozone injection on performance and biomass accumulation of biofilters treating gaseous toluene" by Jinying Xi, Prakit Saingam, Fen Gu, Hong-ying $\mathrm{Hu}$, and Xufei Zhao should refer to DOI 10.1007/s00253-0146248-8, Vol. 99/Issue 1 which is part of the Special Issue "Biotechniques for Air Pollution Control and Bioenergy".

This comment refers to the article available at: http://dx.doi.org/10.1007/ s00253-014-5888-z.

Jinying Xi

xijinying@tsinghua.edu.cn

1 Environmental Simulation and Pollution Control State Key Joint, Laboratory, State Environmental Protection Key Laboratory of Microorganism Application and Risk Control (SMARC), School of Environment, Tsinghua University, 100084 Beijing, People's Republic of China

2 Shenzhen Laboratory of Microorganism Application and Risk Control, Graduate School at Shenzhen, Tsinghua University, 518055 Shenzhen, People's Republic of China 